Document downloaded from:

http://hdl.handle.net/10251/169540

This paper must be cited as:

Galindo, J.; Dolz, V.; Pla Moreno, B.; Ponce-Mora, A. (2020). Advanced exergy analysis of a jet ejector refrigeration cycle used to cool down the intake air in an internal combustion engine. International Journal of Exergy. 32(4):388-411.

https://doi.org/10.1504/IJEX.2020.108948

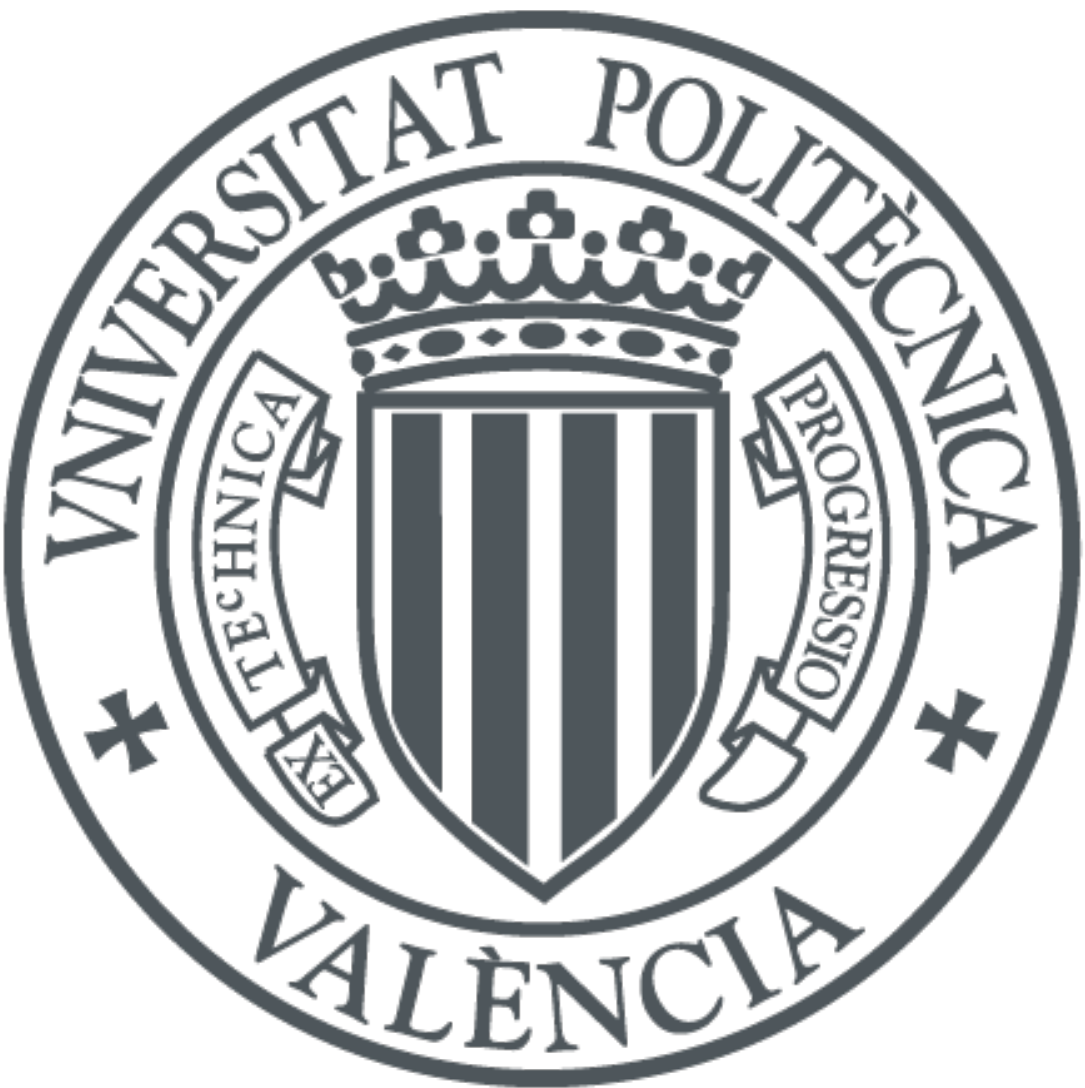

The final publication is available at

https://doi.org/10.1504/IJEX.2020.108948

Copyright Inderscience Enterprises Ltd.

Additional Information 


\title{
ADVANCED EXERGY ANALYSIS OF A JET EJECTOR REFRIGERATION CYCLE USED TO COOL DOWN THE INTAKE AIR IN AN INTERNAL COMBUSTION ENGINE
}

\author{
José Galindo, Vicente Dolz*, Benjamín Pla and Alberto Ponce-Mora \\ CMT - Motores Térmicos, \\ Universitat Politècnica de València, Spain \\ Email: galindo@mot.upv.es \\ Email: vidolrui@mot.upv.es \\ Email: benplamo@mot.upv.es \\ Email: alponmo@mot.upv.es \\ ${ }^{*}$ Corresponding author
}

\begin{abstract}
This paper describes a jet ejection cycle coupled to a 1.5I Diesel engine to reduce the intake air temperature using the waste heat of the exhaust gases. This cycle is evaluated by means of conventional and advanced exergy analysis. The conventional analysis allows to determine the origin and magnitude of the irreversibilities, whereas the advanced analysis sheds light on the mutual interdependences between components and the real improvement potential considering technological limitations. From the conventional exergy analysis it is inferred that more than a half of exergy destruction is due to generator followed by ejector (one third part) and condenser. However, the advanced exergy analysis suggests that ejector plays a prominent role because avoidable endogenous part corresponds to $42 \%$ of total exergy destruction in that component whereas avoidable part of exergy destruction in generator is mostly exogenous (83\%). Hence, exergy destruction could be significantly reduced if improvement efforts are focused on ejector instead of other components like the generator.
\end{abstract}

\section{Keywords}

Waste heat recovery, jet ejector refrigeration cycle, internal combustion engine, performance optimization, genetic algorithm, simple exergy analysis, advanced exergy analysis

\section{NOMENCLATURE}

\section{Acronyms}

$\begin{array}{ll}\text { ICE } & \text { Internal combustion engine } \\ \text { COP } & \text { Coefficient of performance } \\ \text { WHR } & \text { Waste heat recovery } \\ \text { GWP } & \text { Global warming potential }\end{array}$

Notation

Latin 


$\begin{array}{cl}e & \text { Specific exergy }\left(\mathrm{J} \cdot \mathrm{kg}^{-1}\right) \\ \dot{E} & \text { Exergy rate }(\mathrm{W}) \\ h & \text { Specific enthalpy }\left(\mathrm{J} \cdot \mathrm{kg}^{-1}\right) \\ \dot{m} & \text { Mass flow rate }\left(\mathrm{kg} \cdot \mathrm{s}^{-1}\right) \\ P P & \text { Pinch point }\left({ }^{\circ} \mathrm{C}\right) \\ \dot{Q} & \text { Heat exchanger power }(\mathrm{W}) \\ S & \text { Specific entropy }\left(\mathrm{J} \cdot \mathrm{kg}^{-1} \cdot \mathrm{K}^{-1}\right) \\ T & \text { Temperature }\left({ }^{\circ} \mathrm{C}\right) \\ y & \text { Exergy destruction ratio }(-)\end{array}$

\section{Greek letters}

Exergetic efficiency (-)

Ejector entrainment ratio (-)

\section{Subscripts}

$\begin{array}{cl}1-9 & \text { Cycle state points } \\ c o & \text { Condenser } \\ c r i t & \text { Ejector critical operating mode } \\ c v & \text { Control volume } \\ D & \text { Destruction (rate of exergy) } \\ e j & \text { Ejector } \\ e v & \text { Evaporator } \\ e x & \text { ICE exhaust } \\ F & \text { Fuel (rate of exergy) } \\ g e & \text { Generator } \\ i & \text { Inlet } \\ \text { in } & \text { ICE intake } \\ k & \text { k-th element of the cycle } \\ P & \text { Loss (rate of exergy) } \\ o & \text { Outlet } \\ P & \text { Product (rate of exergy) } \\ p r & \text { Primary flow } \\ p m & \text { Pump } \\ r e f & \text { Reference state } \\ s e c & \text { Secondary flow } \\ s & \text { Isentropic conditions } \\ s u p & \text { Superheating } \\ t h & \text { Thermal } \\ t o t & \text { Total } \\ v l & \text { Expansion valve } \\ w & \text { Condenser water }\end{array}$

\section{Superscripts}




$\begin{array}{ll}E N & \text { Endogenous } \\ E X & \text { Exogenous } \\ I D & \text { Ideal conditions } \\ R E & \text { Real conditions } \\ U N & \text { Unavoidable conditions }\end{array}$

\section{INTRODUCTION}

The growing concern about environmental impact of human activity has led to the development of different technologies which support a more efficient use of available resources. Low-grade waste heat energies coming from industrial processes, solar energy, or thermal engines exhaust gases offer potential to be partially recovered, thus contributing to energy savings. This problem has special significance in means of transport that use internal combustion engines. According to U.S. Energy Information Administration $20 \%$ of total energy consumed globally is attributed to means of transportation and it is expected to increase by up to a $40 \%$ in 2040 in the nonOECD countries (Kalghatgi, 2013). Therefore, new technologies are required to meet future regulations in terms of pollutant emissions and fuel consumption (Payri et al., 2015).

In the last few years, the need of cleaner vehicles with lower environmental impact has led to an increase of waste heat recovery (WHR) technologies. On an internal combustion engine (ICE) for automotive applications, approximately, one third of fuel available energy is lost as exhaust waste heat and an additional one third is rejected to the ambient by means of the cooling system. Several approaches have been under investigation in the last decades to unlock this potential:

- Heat to heat, applied specifically during warm up process. This approach has proved to be useful to shorten the time of acquiring nominal temperature, thus contributing to a pollutant emissions and fuel consumption reduction (Luján et al., 2016).

- Turbocompounding systems, which include a power turbine placed at the exhaust line downstream the turbocharger turbine and contributes with additional mechanical power at the shaft with a penalty on exhaust backpressure (Aghaali and Ångström, 2015).

- Thermoelectric generators, which are able to produce electricity by means of Seebek effect. Further development in materials is required since state-of-the-art devices show low efficiency (Hsiao, Chang and Chen, 2010).

- Rankine cycles, which allow to obtain additional mechanical power by using an expander machine. Previously, waste heat has been transferred to the working fluid through an evaporator. For applications with low-grade heat performance is improved by using Rankine cycles with organic fluid (ORC) (Aly, 1988; Dolz et al., 2012; J. Galindo et al., 2015) at the expense of packaging problems.

- Refrigeration technologies like ejection or absorption cycles which use waste heat to generate a cooling capacity (Zegenhagen and Ziegler, 2015c; Novella et al., 2017).

- Other thermodynamic cycles, as Brayton, Stirling or Ericsson cycles which are much less investigated but promising alternatives to ORC in terms of simplicity (J Galindo et al., 2015).

Waste heat recovery systems make use of low-grade energy sources, as a consequence maximizing the energy conversion process is particularly important. Exergy analysis gives 
comprehensive information about source, magnitude and location of system inefficiencies. Simple exergy analysis is a useful approach to identify the thermodynamic inefficiencies in a single component. However it does not provide information about improvement potential and interaction between elements. Conversely, advanced exergy approach identifies which irreversibilities can be attributed to a cycle component itself (endogenous part) or to the interaction of this component with the rest of elements (exogenous part). Likewise, it discriminates between irreversibilities that can be prevented with further technological development of the components (avoidable part) and unachievable performance limited by physical, economic or technological constraints (unavoidable part).

A vast amount of literature has been published in the last few years concerning advanced exergy analysis in different thermal systems: ORC in passenger vehicles and geothermal systems (Galindo et al., 2016; Nami, Nemati and Jabbari Fard, 2017), combined cycle power plants (Cziesla, Tsatsaronis and Gao, 2006; Petrakopoulou et al., 2012; Herrera and Méndez, 2018), Kalina cycles intended for geothermal heat recovery (Fallah et al., 2016), gas turbine applications, (Tatiana Morosuk and Tsatsaronis, 2009; Şöhret et al., 2015), refrigeration systems (T. Morosuk and Tsatsaronis, 2009; Chen, Havtun and Palm, 2015; Gong and Goni Boulama, 2015; Gullo, Elmegaard and Cortella, 2016; Asgari, Noorpoor and Boyaghchi, 2017; Aman, Henshaw and Ting, 2019) or single component improvement, (Li et al., 2015; Vučković, Stojiljković and Vukić, 2015). Despite the extensive literature available, there are no research works dealing with advanced exergy analysis on ejection cycles with the exception of research works carried out by Chen et. al (Chen, Havtun and Palm, 2015) and Ustaoglu et al. (Ustaoglu et al., 2017). However, the former has no particular application and in the latter the ejection cycle is intended for a waste heat recovery system in a cement factory (rotatory kiln).

The originality of the present paper lies in the application of the advanced exergy analysis to an ejection cycle coupled to a 1.5 I Diesel engine in order to reduce the intake air temperature using the waste heat of the engine exhaust gases. Hence, exergy destruction is examined in the Internal Combustion Engine (ICE) working conditions in terms of thermal level available on exhaust line and engine drawn mass flow.

The main objectives of the present paper can be summarized as follows:

- Estimating exergy destruction in each component of an ejection cycle intended for ICE intake ultracooling by means of a simple exergy analysis.

- Splitting exergy destruction into endogenous/exogenous and avoidable/unavoidable parts in order to determine mutual influence of each component, real improvement potential and which elements play a major role.

- Assessing how off-design operating conditions lead to a deterioration of exergy efficiency. That is, how a fixed ejector size different from the optimal affects exergy destruction.

- Determining how exergy destruction takes place on feasible operating points according to performance limitations with special interest on the cycle operating point that minimizes charge air temperature.

\section{EJECTION CYCLE DESCRIPTION}

The ejection refrigeration cycle under investigation is depicted in Figure 1 and the corresponding 
T-s diagram is shown at Figure 2. Conventional ejection cycles can be divided in two loops. In the first one, usually called refrigeration loop, low pressure evaporation of the working fluid takes place, thus absorbing heat from the medium to be cooled (intake air of the engine). In the second one, termed as power loop, working fluid evaporates at high pressure with heat transferred from the hot source (exhaust gases of the engine) and expands into ejector entraining the secondary flow. This entrainment process produces the interaction between both flows. Downstream, the ejector mixing process and subsequent recompression occurs. This mixed flow at a medium temperature and pressure is then condensed rejecting heat to the ambient. A portion of the liquid is recirculated to the pump to complete the power loop and the remainder is expanded in an expansion device upstream the refrigeration loop evaporator.

The refrigerant R134a has been considered in the present study because it is widely implemented in air conditioning systems. However, it has usage limitations (F-Gas Regulation 517/2014 and F-Gas Regulation 842/2006) and it is prohibited in automotive industry since 2011 due to its relatively high GWP (Zegenhagen and Ziegler, 2015b). However this fluid has been used in the present investigation as a model. Key findings could be extended to new generation refrigerants as R1234yf because both refrigerants have similar thermodynamic properties (Reasor, Aute and Radermacher, 2010) and they would be compatible in actual automotive equipment with minor modifications (Lee and Jung, 2012; Vaghela, 2017).

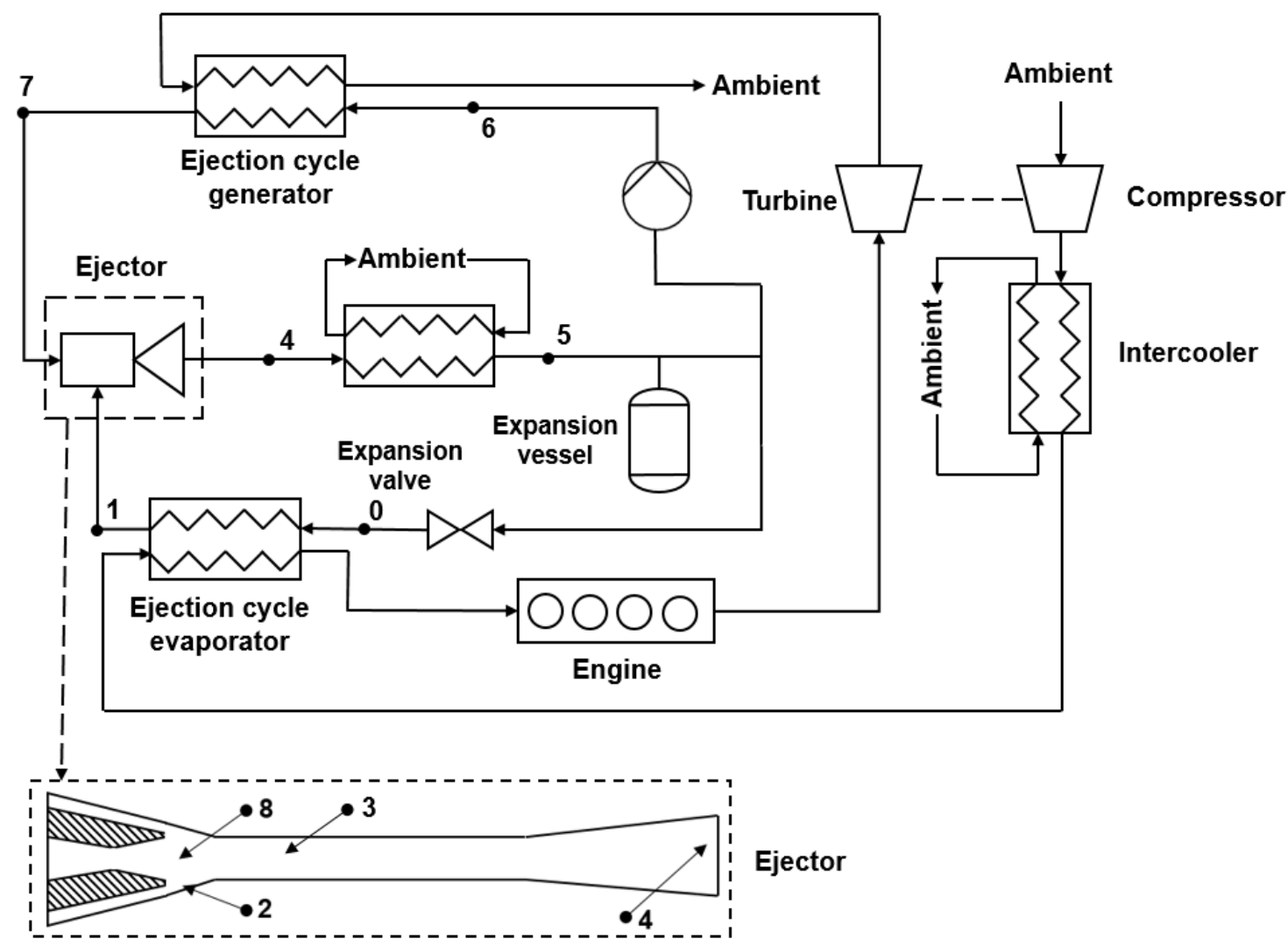

Figure 1. Schematic diagram of ejection cycle coupled to an automotive ICE 


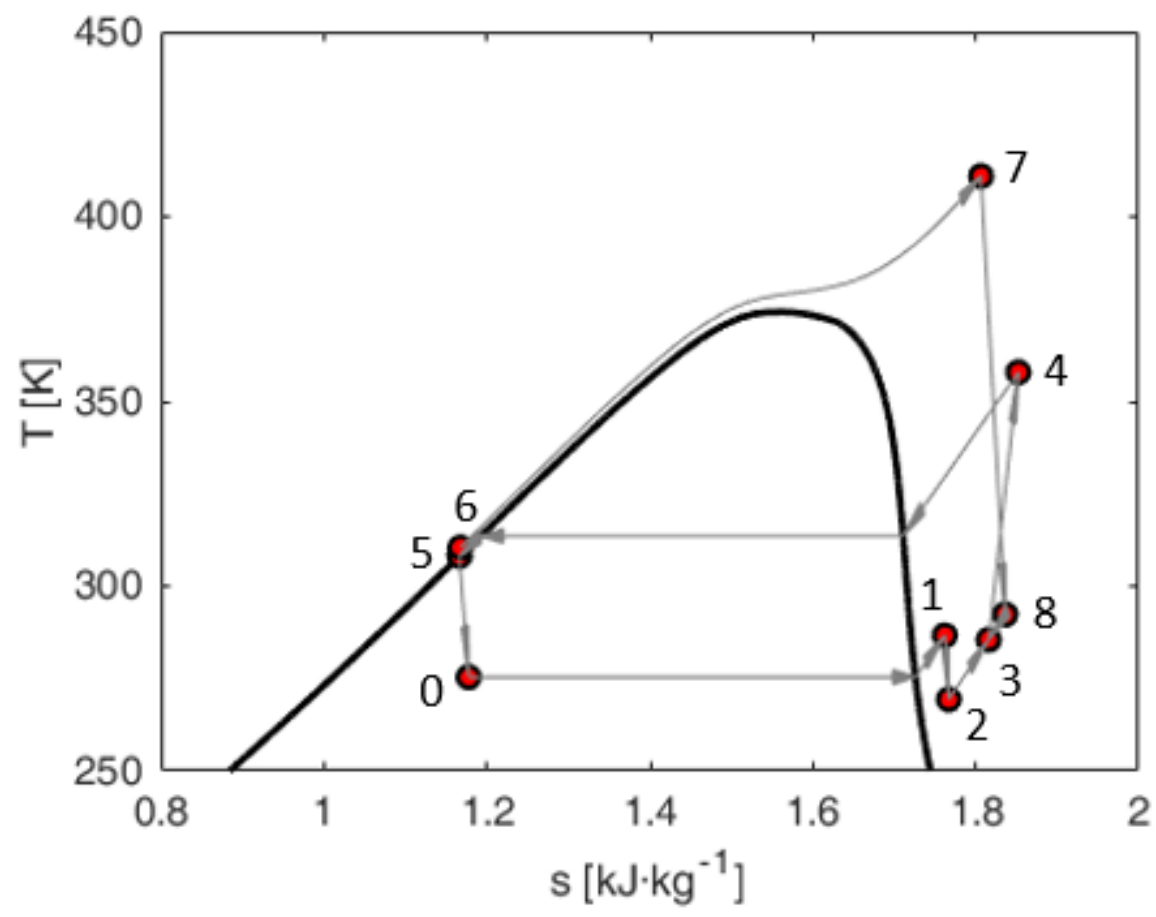

Figure 2. T-s diagram of ejection cycle for R134a (particular case with supercritical conditions at generator)

\section{THERMODYNAMIC ANALYSIS}

In this section the hypothesis assumed in order to generate a simple mathematical model are discussed. Furthermore, energy and exergy balance expressions are listed, as well as resolution strategy, boundary conditions and calculation constraints. The assumptions and restrictions of the mathematical model of the cycle are based on the research work carried out by Galindo et al. (Galindo et al., 2019).

\subsection{Assumptions}

The jet ejection cycle under investigation follows the scheme depicted in Figure 1. References to the state points of this scheme will be made during the whole article. Calculation process is simplified considering the following assumptions:

- Ejection cycle under investigation works in steady-state conditions.

- Thermodynamic state of R134a is determined using the Coolprop database.

- In a defined working condition of the IC engine, the intake air and the exhaust gases are considered as a perfect gas. Intake/exhaust temperature and mass flow are assumed to be constant. 
- Ejector double-choking mode is assumed as the only admissible mode.

- For primary flow expansion at converging-diverging nozzle one-dimensional model with real gas effects proposed by Zegenhagen and Ziegler (Zegenhagen and Ziegler, 2015a) has been used.

- Pump efficiency is assumed to be constant and its pressure rise is modelled by introducing an isentropic efficiency.

- In ideal conditions, the expansion process is assumed as isentropic and in other cases, we assume this expansion process in an isenthalpic valve.

- Upstream the cooling evaporator, a mixture of liquid and vapor as well as subcooled liquid are considered as valid states.

- Both subcritical and supercritical are considered as feasible heating processes at the generator.

- Refrigerant leaving the condenser, evaporator and generator is not necessarily at saturated conditions.

- Pressure losses are neglected in the three heat exchangers and the junction tubes.

- Real, unavoidable and ideal conditions are shown in Table 1.

\begin{tabular}{|c|c|c|c|}
\hline & Real & Unavoidable & Ideal \\
\hline Pump & $\eta_{p m}=85 \%$ & $\eta_{p m}=90 \%$ & $\eta_{p m}=100 \%$ \\
\hline $\begin{array}{l}\text { Expansion } \\
\text { valve }\end{array}$ & Isenthalpic & Isenthalpic & Isentropic \\
\hline Condenser & $\mathrm{PP}=7{ }^{\circ} \mathrm{C}$ & $\mathrm{PP}=3{ }^{\circ} \mathrm{C}$ & $\mathrm{PP}=0^{\circ} \mathrm{C}$ \\
\hline Evaporator & $\mathrm{PP}=7^{\circ} \mathrm{C}$ & $\mathrm{PP}=3{ }^{\circ} \mathrm{C}$ & $\mathrm{PP}=0{ }^{\circ} \mathrm{C}$ \\
\hline Generator & $\mathrm{PP}=7^{\circ} \mathrm{C}$ & $\mathrm{PP}=3{ }^{\circ} \mathrm{C}$ & $\mathrm{PP}=0^{\circ} \mathrm{C}$ \\
\hline Ejector & $\begin{array}{c}\text { Entrainment } \\
\text { ratio given by } \\
\text { the ejector map } \\
\text { (Zegenhagen } \\
\text { and Ziegler, } \\
2015 \mathrm{~b}, 2015 \mathrm{c} \text { ). } \\
\eta_{e j}=45 \%\end{array}$ & $\begin{array}{c}\text { Entrainment } \\
\text { ratio given by } \\
\text { unavoidable } \\
\text { process } \\
\text { (compressions } \\
\text { and expansions } \\
\text { modelled with } \\
\text { an isentropic } \\
\text { efficiency). } \\
\eta_{e j}=75 \%\end{array}$ & $\begin{array}{l}\text { Entrainment ratio } \\
\text { given by an } \\
\text { idealized process } \\
\text { (entropy } \\
\text { conservation } \\
\text { (McGovern, } \\
\text { Prakash Narayan } \\
\text { and Lienhard, } \\
\text { 2012; Chen, } \\
\text { Havtun and Palm, } \\
2015) \text { ). } \\
\eta_{e j}=100 \%\end{array}$ \\
\hline
\end{tabular}

Table 1. Hypothesis used for the real, unavoidable and ideal cycles

The assumptions adopted in Table 1 to model ejector behaviour in each case are explained in more detail below:

- Ejector efficiency $\left(\eta_{e j}\right)$ is given by ASHRAE definition (Little and Garimella, 2011) (Equation (1)) and it provides information about heat losses. It must be noted that subscripts of Equation (1) correspond to states depicted in Figure 1 and Figure 2. In real case, ejector efficiency has been selected according to experimental data presented by Huang et al. (Huang et al., 1999). ASHRAE definition of efficiency corresponds in the mentioned research work to a heat loss of approximately $5 \%$ between energy available at ejector inlets and outlet. On the contrary, heat losses are neglected in the ideal case. 


$$
\eta_{e j}=\frac{\left(\dot{m}_{p r}+\dot{m}_{s e c}\right) \cdot\left(h_{4}-h_{1}\right)}{\dot{m}_{p r} \cdot\left(h_{7}-h_{1}\right)}
$$

- Ejector map used in the present paper to model ejector component in the real cycle corresponds to a prototype used by Zegenhagen and Ziegler (Zegenhagen and Ziegler, 2015b, 2015c) and it was implemented in a refrigeration system intended for the same purpose (ICE intake cooling). Its performance has been experimentally investigated using R134a as refrigerant and the range of operating pressures and temperatures is similar in the present paper. For the present investigation only ejector critical mode has practical relevance and this mode can be modelled by using Equation (2).

$$
\omega_{\text {crit }}=1.13+0.378 \cdot \ln \left(\pi_{1,7}\right)
$$

On the other hand, ejector malfunctioning modes (backflow and subcritical modes) are not relevant in the present study. Ejector critical map applicability is delimited by a critical backpressure ratio of 0.23 also determined experimentally.

- In the ideal case, the ejector entrainment ratio is derived from entropy conservation and energy balance neglecting heat losses.

- The unavoidable ejector approach assumes also double-choking operating mode and subsequent flow expansions and compression have been modelled with an isentropic efficiency. Secondary flow expansion has been deemed as an isentropic process, with an unavoidable isentropic efficiency $\left(\eta_{s e c, s}=0.95\right)$ until reaching sonic conditions. Isentropic efficiencies are introduced to model ejector internal losses due to friction, mixing and shock recompression. Resulting pressure of the secondary flow expansion (2) has been considered equal to the corresponding value at (8) which is a common approach in the literature (Huang et al., 1999), (Chen et al., 2013). Resulting state at (3) is determined weighting enthalpy of (8) and (2) with primary and secondary mass flows, respectively. With previous assumptions and ejector efficiency, both ejector outlet conditions and entrainment ratio can be determined.

\subsection{Energy balance analysis}

Power balance equations concerning the main elements of Figure 1 and COP definition are presented below. Energy balance in the heat exchangers takes into account the heat transferred in the refrigerant side and also at the ICE exhaust line (generator), cooling water (condenser) and ICE intake line (evaporator).

$$
\begin{gathered}
\dot{Q}_{g e}=\dot{m}_{e x} \cdot c_{p, e x} \cdot\left(T_{i, e x}-T_{o, e x}\right)=\dot{m}_{p r} \cdot\left(h_{7}-h_{6}\right) \\
\dot{Q}_{c o}=\dot{m}_{w} \cdot c_{p . w} \cdot\left(T_{o, w}-T_{i, w}\right)=\left(\dot{m}_{p r}+\dot{m}_{s e c}\right) \cdot\left(h_{4}-h_{5}\right)
\end{gathered}
$$




$$
\begin{gathered}
\dot{Q}_{e v}=\dot{m}_{i n} \cdot c_{p, i n} \cdot\left(T_{i, i n}-T_{o, i n}\right)=\dot{m}_{s e c} \cdot\left(h_{1}-h_{0}\right) \\
\dot{W}_{p m}=\dot{m}_{p r} \cdot\left(h_{6}-h_{5}\right) \\
\operatorname{COP} P_{t h}=\frac{\dot{Q}_{e v}}{\dot{Q}_{g e}}
\end{gathered}
$$

\subsection{Exergy balance analysis}

In order to optimize cycle performance, it is necessary to determine the magnitude of exergy destruction and its origin in each element of the cycle. In this subsection both conventional and advanced approaches are described to quantify exergy destruction and to estimate the real improvement potential.

\section{Conventional exergy analysis}

By computing exergy rate of fuel in the k-th component $\left(\dot{E}_{F, k}\right)$ and exergy rate of products $\left(\dot{E}_{P, k}\right)$ exergy destruction rate $\left(\dot{E}_{D, k}\right)$ associated with the internal irreversibilities occurring in the k-th element can be determined. Therefore, an exergy efficiency and an exergy destruction ratio $\left(\varepsilon_{k}, y_{D, k}\right)$ can be defined referring to the irreversibilities in single components and the contribution to the overall system $\left(y_{D, k}^{*}\right)$. Basic equations of exergy analysis in the k-th cycle component are listed below, where $\dot{E}_{L, t o t}$ corresponds to external exergy loss in the overall system.

The exergy rate of fuel in the k-th element can be defined as:

$$
\dot{E}_{F, k}=\dot{E}_{P, k}+\dot{E}_{D, k}
$$

The exergy rate of fuel in the in the overall system can be expressed as follows:

$$
\dot{E}_{F, t o t}=\dot{E}_{P, t o t}+\dot{E}_{D, t o t}+\dot{E}_{L, t o t}
$$

The exergy efficiency, the exergy destruction ratio and the contribution of each component to overall exergy destruction are computed in Equations 10-12.

$$
\begin{gathered}
\varepsilon_{k}=\frac{\dot{E}_{P, k}}{\dot{E}_{F, k}}=1-\frac{\dot{E}_{D, k}}{\dot{E}_{F, k}} \\
y_{D, k}=\frac{\dot{E}_{D, k}}{\dot{E}_{F, k}}
\end{gathered}
$$




$$
y_{D, k}^{*}=\frac{\dot{E}_{D, k}}{\dot{E}_{D, t o t}}
$$

Equation (13) corresponds to general expression for determining exergy destruction in steadystate conditions. Specific exergy corresponding to the chemical part is excluded because there are no chemical reactions in the thermodynamic cycle under investigation.

$$
\sum\left(1-\frac{T_{r e f}}{T}\right) \cdot \dot{Q}-\dot{W}_{c v}+\sum_{i} \dot{m}_{i, k} \cdot e_{i, k}-\sum_{o} \dot{m}_{o, k} \cdot e_{o, k}-\dot{E}_{D, k}=0
$$

The first term of Equation (13) is null if heat transfer between system boundaries is neglected and subscript $r$ ef refers to environmental condition $\left(25^{\circ} \mathrm{C}\right.$ and $\left.1 \mathrm{~atm}\right)$. In the second and third terms the parameter $e$ corresponds to specific flow exergy neglecting the kinetic and potential contribution:

$$
e=h-h_{r e f}-T_{r e f} \cdot\left(s-s_{r e f}\right)
$$

Based on the above general expressions, exergy destruction equations for the conventional analysis are presented in Table 2:

\begin{tabular}{|c|c|}
\hline Generator & $\dot{E}_{D, g e}=\dot{m}_{p r} \cdot\left(e_{6}-e_{7}\right)+\dot{m}_{e x} \cdot\left(e_{i, e x}-e_{o, e x}\right)$ \\
\hline Condenser & $\dot{E}_{D, c o}=\left(\dot{m}_{p r}+\dot{m}_{s e c}\right) \cdot\left(e_{4}-e_{5}\right)+\dot{m}_{w} \cdot\left(e_{i, w}-e_{o, w}\right)$ \\
\hline Evaporator & $\dot{E}_{D, e v}=\dot{m}_{s e c} \cdot\left(e_{0}-e_{1}\right)+\dot{m}_{i n} \cdot\left(e_{i, i n}-e_{o, i n}\right)$ \\
\hline Pump & $\dot{E}_{D, p m}=\dot{m}_{p r} \cdot\left(e_{5}-e_{6}\right)-\dot{W}_{p m}$ \\
\hline Expansion valve & $\dot{E}_{D, v l}=\dot{m}_{s e c} \cdot\left(e_{5}-e_{0}\right)$ \\
\hline Ejector & $\dot{E}_{D, e j}=\dot{m}_{p r} \cdot\left(e_{7}-e_{4}\right)+\dot{m}_{s e c} \cdot\left(e_{1}-e_{4}\right)$ \\
\hline
\end{tabular}

Table 2. Exergy destruction in each cycle component

\section{Advanced exergy analysis}

For further analysis of the cycle inefficiencies advanced exergy analysis is essential. This approach provides clearer insights about exergy destruction sources and the real improvement potential according to technological limitations. The main objective is to branch exergy destruction into endogenous/exogenous and avoidable/unavoidable parts:

- Endogenous/exogenous exergy destruction in the k-th component: Endogenous exergy destruction part in the k-th component $\left(\dot{E}_{D, k}^{E N}\right)$ can be attributed to the irreversibilities occurring at the component itself and exogenous part is caused by the interaction with other elements. Endogenous exergy destruction is computed with the so-called hybrid cycles in which the component under investigation operates in real conditions and the rest of the elements have an idealized performance (Chen, Havtun and Palm, 2015; Fallah et al., 2016; Galindo et al., 2016). Exogenous exergy destruction in the k-th element $\left(\dot{E}_{D, k}^{E X}\right)$ is the difference between exergy destruction provided by conventional analysis and endogenous exergy destruction, both in the k-th element (Table 3). 
- Avoidable/unavoidable exergy destruction in the k-th component: Avoidable exergy destruction $\left(\dot{E}_{D, k}^{A V}\right)$ refers to exergy destruction part that could be avoided if all components were improved as far as possible. Hence, this part of exergy destruction would be recoverable with further technical development. Unavoidable exergy destruction part in the k-th component $\left(\dot{E}_{D, k}^{U N}\right)$ corresponds with potential improvement on exergy efficiency if technological limitations could be overcome. Unavoidable exergy destruction in the k-th component $\left(\dot{E}_{D, k}^{U N}\right)$ is computed assuming that all the components work in unavoidable conditions (Table 3 ).

\begin{tabular}{|c|c|}
\hline$\dot{E}_{D, k}^{E N}$ & Ideal-real hybrid cycles (Chen, Havtun and Palm, 2015; Fallah et al., 2016; Galindo et \\
& al., 2016) \\
\hline$\dot{E}_{D, k}^{E X}$ & $\dot{E}_{D, k}-\dot{E}_{D, k}^{E N}$ \\
\hline$\dot{E}_{D, k}^{U N}$ & All components work in unavoidable conditions (Fallah et al., 2016) \\
\hline$\dot{E}_{D, k}^{A V}$ & $\dot{E}_{D, k}-\dot{E}_{D, k}^{U N}$ \\
\hline
\end{tabular}

Table 3. Endogenous/Exogenous and Avoidable/Unavoidable exergy determination

\section{- Combination of the splitting in the k-th component:}

The unavoidable endogenous $\left(\dot{E}_{D, k}^{E N . U N}\right)$, the avoidable endogenous $\left(\dot{E}_{D, k}^{E N . A V}\right)$, the avoidable exogenous $\left(\dot{E}_{D, k}^{E X . A V}\right)$ and the unavoidable exogenous $\left(\dot{E}_{D, k}^{E X . U N}\right)$ parts of exergy destruction in the k-th component are calculated following the expressions provided in Table 4.

\begin{tabular}{|l|c|}
\hline$\dot{E}_{D, k}^{E N . U N}$ & $\dot{E}_{P, k}^{E N} \cdot\left(\frac{\dot{E}_{D}}{\dot{E}_{P}}\right)_{k}^{U N}$ (Galindo et al., 2016) \\
\hline$\dot{E}_{D, k}^{E N, A V}$ & $\dot{E}_{D, k}^{E N}-\dot{E}_{D, k}^{E N, U N}$ \\
\hline$\dot{E}_{D, k}^{E X, A V}$ & $\dot{E}_{D, k}^{E X}-\dot{E}_{D, k}^{E X, U N}$ \\
\hline$\dot{E}_{D, k}^{E X, U N}$ & $\dot{E}_{D, k}^{U N}-\dot{E}_{D, k}^{E N, U N}$ \\
\hline
\end{tabular}

Table 4. Advanced exergy analysis splitting

\subsection{Boundary conditions}

The ejection cycle under investigation in the present paper works under specific conditions (exhaust thermal level and intake/exhaust mass flow rate) of a 1.5I Diesel engine. Charge air temperature, temperature downstream the turbine as well as mass flows of engine operating points under investigation come from an engine test bench.

\begin{tabular}{|c|c|c|c|c|}
\hline Engine operating point & $\dot{m}_{\text {in }}\left[\mathrm{kg} \cdot \mathrm{s}^{-1}\right]$ & $\dot{m}_{e x}\left[\mathrm{~kg} \cdot \mathrm{s}^{-1}\right]$ & $T_{i, i n}\left[{ }^{\circ} \mathrm{C}\right]$ & $T_{i, e x}\left[{ }^{\circ} \mathrm{C}\right]$ \\
\hline $2000 \mathrm{rpm}, 50 \%$ load & 0.0418 & 0.0437 & 40.54 & 416.94 \\
\hline $2500 \mathrm{rpm}, 75 \%$ load & 0.0761 & 0.0794 & 39.22 & 473.46 \\
\hline
\end{tabular}


Table 5. Experimental engine data used as boundary conditions

Furthermore, ambient conditions at condenser water side are assumed, $T_{o, w}=35{ }^{\circ} \mathrm{C}$ and $T_{i, w}=25^{\circ} \mathrm{C}$.

\subsection{Design and off-design approaches}

Genetic algorithm has been used in both conventional and advanced exergy analysis to find those cycle operating points that satisfy objectives and constraints of each specific case. Depending on the study there are some differences in approach:

- In the conventional exergy analysis exergy destruction has been determined for a single engine operating point ( $2000 \mathrm{rpm}, 50 \%$ load). For this boundary conditions ejector scaling factor $(\beta)$ has been considered as a design variable together with variables shown at Table 6 in order to find the optimum values that minimize charge air temperature. It must be noted that the scaling factor refers to the original geometry studied by Zegenhagen and Ziegler (Zegenhagen and Ziegler, 2015b, 2015c).

- Subsequently, exergy destruction in off-design operating conditions has been quantified. To achieve this goal ejection cycle performance has been reassessed in a different engine operating point ( $2500 \mathrm{rpm}, 75 \%$ load), however, ejector size and therefore scaling factor is fixed in this case and it corresponds to the optimum of the previous study. This approach corresponds to a more realistic situation in which a particular ejector design is selected and implemented in the vehicle. In this case exhaust mass flow has been considered as a control variable due to the hypothetical surplus of heat in the exhaust line. The rest of variables involved in the study are shown in Table 7.

\begin{tabular}{|c|c|c|c|}
\hline Variable & Description & Range & Units \\
\hline$P_{5}$ & Intermediate pressure & $5-15$ & bar \\
\hline$T_{1, \text { sup }}$ & Evaporator superheating temperature & $0-60$ & ${ }^{\circ} \mathrm{C}$ \\
\hline$\Delta P$ & Pressure drop at expansion valve & $5-15$ & bar \\
\hline$\beta$ & Ejector scaling factor & $0.5-1.5$ & - \\
\hline Optimization objective & \multicolumn{2}{|c|}{ Minimization of charge air temperature } \\
\hline
\end{tabular}

Table 6. Genetic algorithm inputs for the design operating conditions in the conventional exergy analysis

\begin{tabular}{|c|c|c|c|}
\hline Variable & Description & Range & Units \\
\hline$P_{5}$ & Intermediate pressure & $5-15$ & bar \\
\hline$T_{1, \text { sup }}$ & Evaporator superheating temperature & $0-60$ & ${ }^{\circ} \mathrm{C}$ \\
\hline$\Delta P$ & Pressure drop at expansion valve & $5-15$ & bar \\
\hline$\alpha$ & Fraction of engine exhaust mass flow & $0-1$ & - \\
\hline Optimization objective & \multicolumn{3}{|c|}{ Minimization of charge air temperature } \\
\hline
\end{tabular}


Table 7. Genetic algorithm inputs for the off-design operating conditions in the conventional exergy analysis

- The advanced exergy analysis is focused on a particular engine operating point (2000 rpm, $50 \%$ load), therefore methodology differs from conventional exergy analysis. Firstly, real operating conditions of Table 1 are considered and reduction of engine intake temperature is set as the optimization goal. Minimum achievable temperature in the real cycle has been taken as the reference value. Then ideal, unavoidable and hybrid cycles have been evaluated setting the reference cooling capacity and in each case primary mass flow reduction has been considered as the optimization target. It must be noted that a reduction in cycle mass flow has a positive impact on exergy destruction. Therefore, variables involved in this optimization process are a combination of those shown in the conventional exergy analysis (Table 8).

\begin{tabular}{|c|c|c|c|}
\hline Variable & Description & Range & Units \\
\hline$P_{5}$ & Intermediate pressure & $5-15$ & bar \\
\hline$T_{1, \text { sup }}$ & Evaporator superheating temperature & $0-60$ & ${ }^{\circ} \mathrm{C}$ \\
\hline$\Delta P$ & Pressure drop at expansion valve & $5-15$ & bar \\
\hline$\alpha$ & Fraction of engine exhaust mass flow & $0-1$ & - \\
\hline$\beta$ & Ejector scaling factor & $0.5-1.5$ & - \\
\hline Optimization objective & \multicolumn{2}{|c|}{ Minimization of cycle primary mass flow } \\
\hline
\end{tabular}

Table 8. Genetic algorithm inputs for the advanced exergy analysis

The aforementioned calculations must satisfy the following constraints to consider an operating point as feasible:

- Only ejector double-choking mode has been considered as valid.

- Refrigerant at ejector primary inlet (7), secondary inlet (1) and outlet (4) must be superheated vapor.

- $\quad$ Refrigerant leaving the condenser (5) must be subcooled liquid.

- Unstable system operation has been reported in literature due to the condensation effect on primary nozzle expansion (Grazzini, Milazzo and Piazzini, 2011). Hence, enthalpy after secondary (2) and primary (8) flow expansions must be higher than vapor saturated enthalpy at the corresponding pressure to avoid liquid inside the ejector. Primary flow expansion process has been determined following the real gas expansion model proposed by Zegenhagen and Ziegler (Zegenhagen and Ziegler, 2015a).

- Pinch points during heat exchange process in both condenser, evaporator and generator must be greater than values of Table 1 assuming counterflow heat exchangers.

\section{SIMULATION RESULTS AND DISCUSSION}


In this section the results from the conventional and advanced exergy analysis are presented. The cycle operating point that minimizes engine charge air temperature is selected from the conventional exergy analysis and subsequently the real improvement potential is exhaustively investigated in the advanced exergy analysis. In addition, the influence of off-design engine operating condition over a fixed ejector cycle configuration is assessed.

\subsection{Conventional exergy analysis}

\section{Design study}

Conventional exergy analysis has been carried out with the real cycle conditions shown at Table 1. Figure 3 depicts a set of cycle operating points obtained varying the cycle operating conditions and the ejector scale (Table 6). All of them satisfy pinch point constraints and result from an optimization process where minimization of the charge air temperature is set as target. According to Figure 3 improving efforts should be concentrated on ejector and generator since these components have the highest exergy destruction: generator [1.4 kW, $3.07 \mathrm{~kW}$ ] and ejector [1.79 kW, $3.19 \mathrm{~kW}$ ]. Exergy destruction at the condenser is represented at Figure 5 and it is not negligible [0.43 kW, $0.95 \mathrm{~kW}$ ]. Exergy destruction at evaporator, pump and expansion valve are much less significant. Total exergy destruction of ejection cycle remains almost constant and it ranges from $5.48 \mathrm{~kW}$ to $5.55 \mathrm{~kW}$ as can be seen in Figure 4. Figure 4 and Figure 5 depict that a strong interaction between exergy destruction at generator and ejector/condenser exists. The trend reflected by scatter plot shows that high exergy destruction at generator imply low exergy destruction at ejector and condenser and vice versa. Two significant cases showing an opposite trend have been highlighted in Figure 3, Figure 4 and Figure 5 . First case $\left(C_{1}\right)$ corresponds to an operating point with the lowest exergy destruction at the generator. Low exergy destruction is due to significant superheating of primary flow leaving the generator. In fact, case $C_{1}$ is close to the refrigerant degradation temperature. Therefore, high thermal level of engine exhaust is used to largely increase refrigerant temperature leaving the generator. Since ejector inlet temperature is high heat losses might be significant according to ASHRAE efficiency definition, leading to a poor exergy efficiency. Despite this, temperature of the flow leaving the ejector in case $C_{1}$ is still high, therefore, significant heat rejection at the condenser is required. For this reason exergy destruction at the condenser is also significant. In case of a more adiabatic ejector exergy destruction would inevitably occur at condenser due to imperative heat rejection.

On the other hand, the second case $\left(C_{2}\right)$ corresponds to that feasible operating point with the lowest charge air temperature $\left(9 .{ }^{\circ} \mathrm{C}\right)$. In this case only a small fraction of the heat power available at engine exhaust is transferred to the refrigerant. Hence, generator is the main source of exergy destruction whereas exergy destruction occurring at ejector and condenser is lessened. 


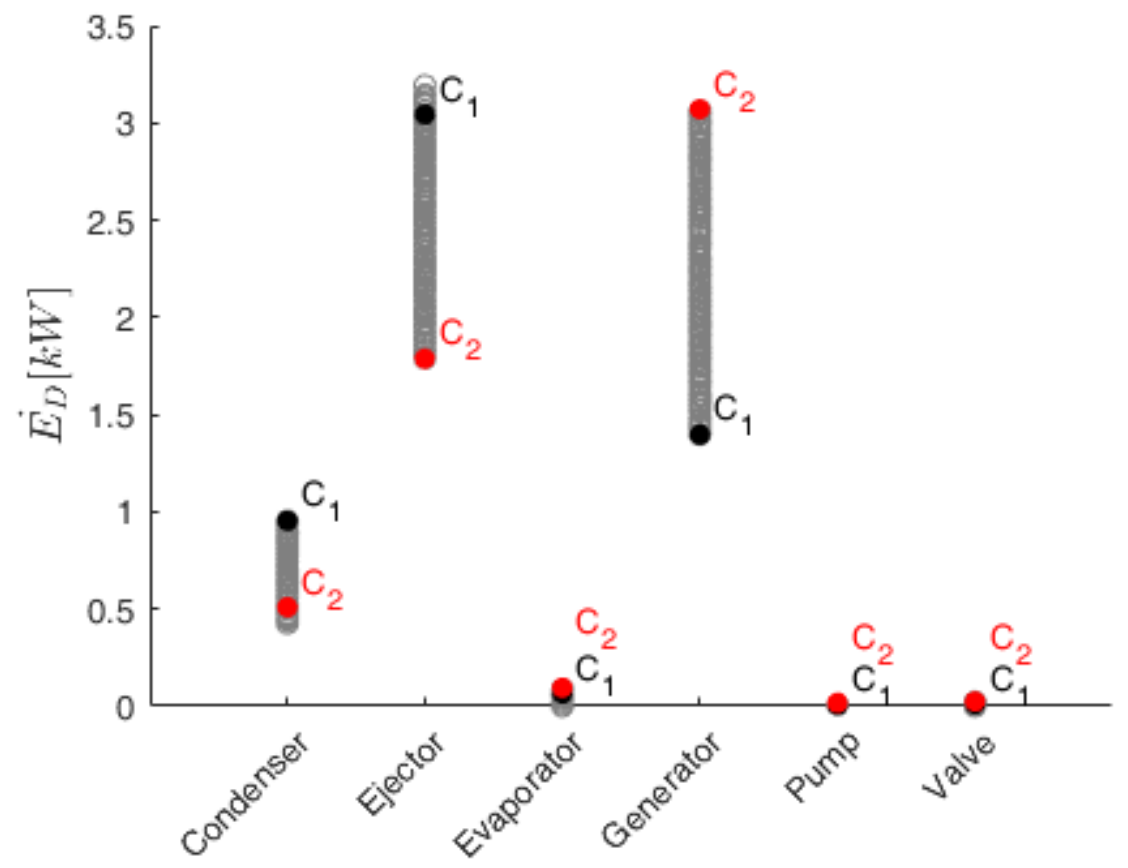

Figure 3. Exergy destruction in each element for feasible operating points (design conditions)

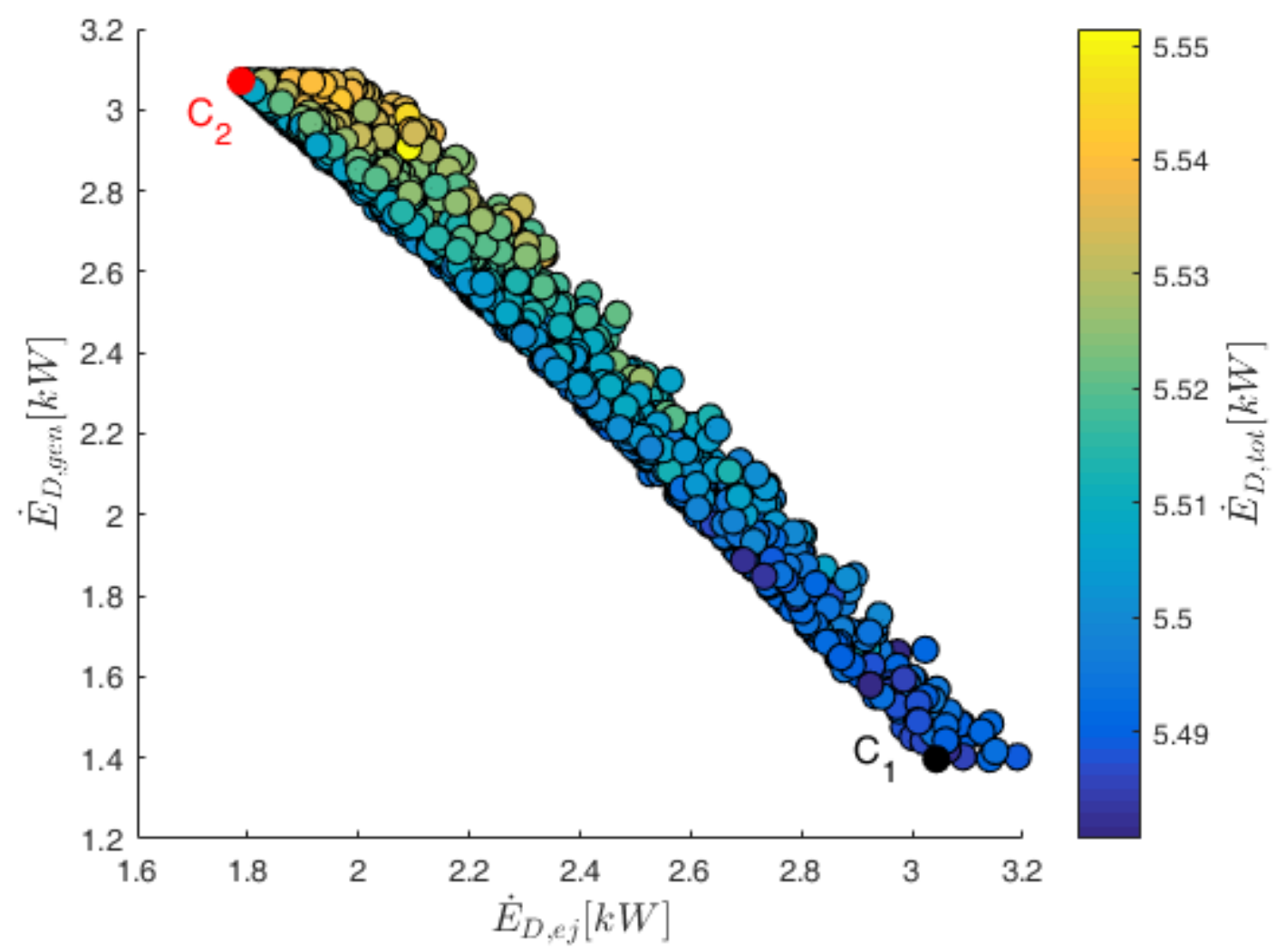

Figure 4. Influence of exergy destruction in the ejector and generator vs. total exergy destruction 


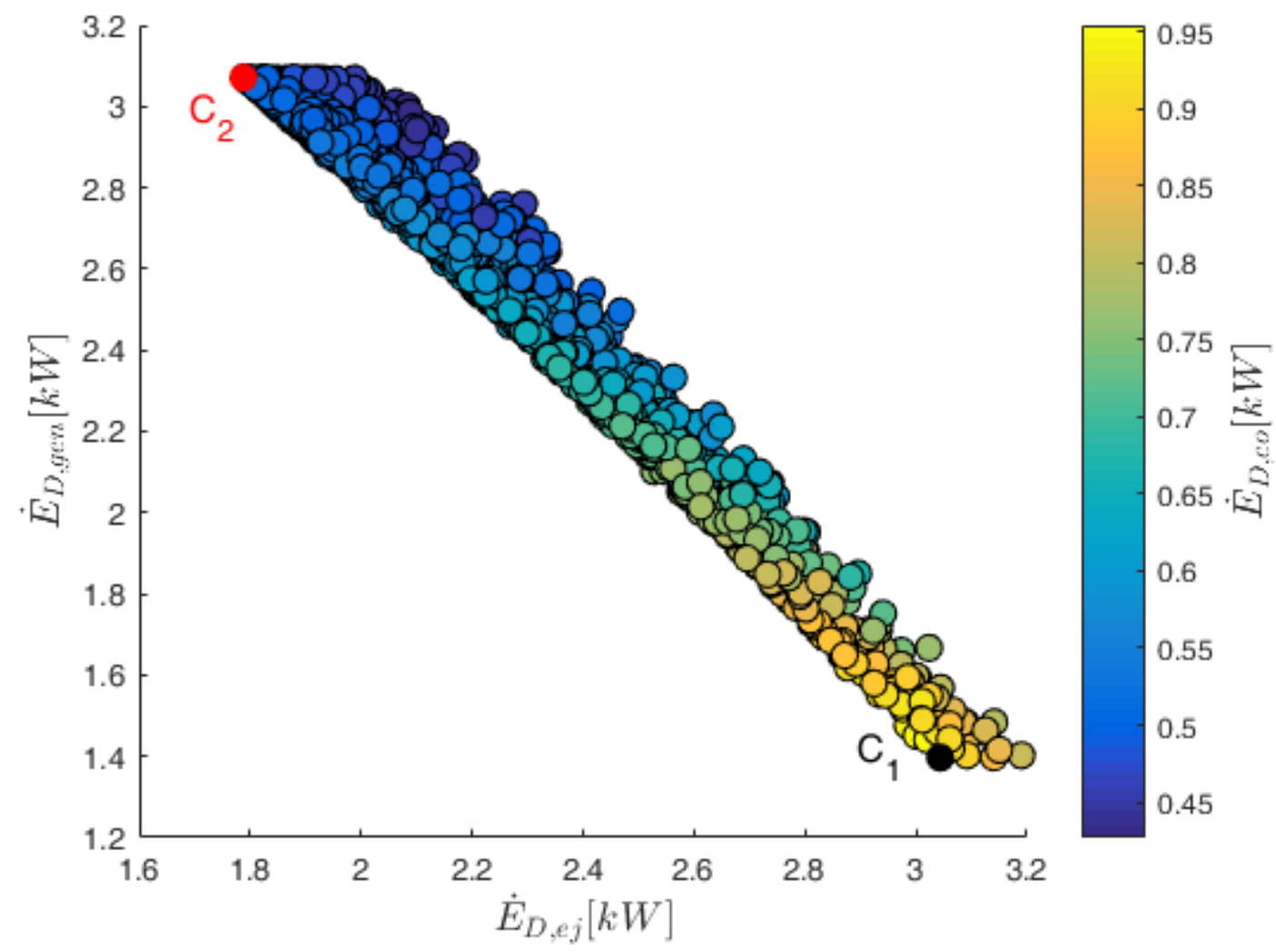

Figure 5. Influence of exergy destruction in the ejector and generator vs. exergy destruction at condenser

The second operating point $\left(C_{2}\right)$ has been selected in the following to discuss the results from the conventional and advanced exergy analysis because it presents the lowest charge air temperature. Hence, this is the operating point showing best performance. In the advanced exergy analysis cooling capacity is the same in the three cases under investigation, i.e, real, unavoidable and ideal cycle. With this assumption, as ejector component is improved entrainment ratio increases leading to a lower primary mass flow required per unit of secondary mas flow. This causes a positive effect over exergy destruction and overall cycle COP. Illustrating the previous trend, $\omega^{R E}=0.128, C O P_{t h}^{R E}=0.097$ and $\dot{E}_{D, t o t}^{R E}=5.51 \mathrm{~kW}$ in the real cycle whereas $\omega^{U N}=0.198, C O P_{t h}^{U N}=0.147$ and $\dot{E}_{D, t o t}^{U N}=3.60 \mathrm{~kW}$ could be achieved with further improvement within technological limitations (unavoidable cycle) and $\omega^{I D}=0.886, C O P_{t h}^{I D}=$ 0.604 and $\dot{E}_{D, \text { tot }}^{I D}=0.86 \mathrm{~kW}$ if all components behave ideally (ideal cycle). Exergy destruction, exergy of products, exergy fuel and exergetic efficiencies for the real, unavoidable and ideal cycles are presented in Table 9, Table 10, and Table 11, respectively. Figure 6 provides supplementary information to exergy splitting in the conventional analysis. It must be noted that cooling capacity requirement is the same in the real, unavoidable and ideal cycles.

In the case under investigation $\left(C_{2}\right)$ the major part of exergy destruction ( $\left.>55 \%\right)$ can be attributed to the generator, followed by the ejector and the condenser. According to the conventional exergy analysis improvement efforts should be applied following that priority. However, conventional exergy analysis does not allow to discriminate between exergy destruction occurring at the component under investigation (endogenous part) and the part derived from the interaction between the rest of the components (exogenous part). Furthermore, it does not 
allow to distinguish between the avoidable and the unavoidable parts of exergy destruction. Therefore, the advanced exergy analysis is essential to compute real enhancement potential.

\begin{tabular}{|c|c|c|c|c|c|c|}
\cline { 2 - 7 } \multicolumn{1}{c|}{} & Generator & Evaporator & Condenser & Expansion valve & Pump & Ejector \\
\hline$\dot{E}_{F}[\mathrm{~kW}]$ & 5.54 & 0.10 & 0.73 & 0.26 & 0.19 & 1.99 \\
\hline$\dot{E}_{P}[\mathrm{~kW}]$ & 2.46 & 0.00 & 0.22 & 0.24 & 0.17 & 0.20 \\
\hline$\dot{E}_{D}[\mathrm{~kW}]$ & 3.07 & 0.10 & 0.51 & 0.02 & 0.02 & 1.79 \\
\hline$\varepsilon_{k}[\%]$ & 44.5 & 1.7 & 29.7 & 90.5 & 90.4 & 10.3 \\
\hline$y_{D, k}[\%]$ & 55.5 & 98.3 & 70.3 & 9.5 & 9.6 & 89.7 \\
\hline$y_{D, k}^{*}[\%]$ & 55.8 & 1.7 & 9.3 & 0.5 & 0.3 & 32.5 \\
\hline
\end{tabular}

Table 9. Conventional exergy analysis results for the real cycle

\begin{tabular}{|c|c|c|c|c|c|c|}
\cline { 2 - 7 } \multicolumn{1}{c|}{} & Generator & Evaporator & Condenser & Expansion valve & Pump & Ejector \\
\hline$\dot{E}_{F}[\mathrm{~kW}]$ & 3.66 & 0.11 & 0.51 & 0.27 & 0.10 & 1.27 \\
\hline$\dot{E}_{P}[\mathrm{~kW}]$ & 1.59 & 0.00 & 0.16 & 0.24 & 0.10 & 0.22 \\
\hline$\dot{E}_{D}[\mathrm{~kW}]$ & 2.06 & 0.10 & 0.35 & 0.03 & 0.00 & 1.05 \\
\hline$\varepsilon_{k}[\%]$ & 43.6 & 1.5 & 31.4 & 89.8 & 95.2 & 17.1 \\
\hline$y_{D, k}[\%]$ & 56.4 & 98.5 & 68.6 & 10.2 & 4.8 & 82.9 \\
\hline$y_{D, k}^{*}[\%]$ & 57.4 & 2.9 & 9.7 & 0.8 & 0.1 & 29.2 \\
\hline
\end{tabular}

Table 10. Conventional exergy analysis results for the unavoidable cycle

\begin{tabular}{|c|c|c|c|c|c|c|}
\cline { 2 - 7 } \multicolumn{1}{c|}{} & Generator & Evaporator & Condenser & Expansion valve & Pump & Ejector \\
\hline$\dot{E}_{F}[\mathrm{~kW}]$ & 0.89 & 0.20 & 0.14 & 0.30 & 0.03 & 0.33 \\
\hline$\dot{E}_{P}[\mathrm{~kW}]$ & 0.38 & 0.00 & 0.06 & 0.24 & 0.03 & 0.33 \\
\hline$\dot{E}_{D}[\mathrm{~kW}]$ & 0.52 & 0.20 & 0.08 & 0.07 & 0.00 & 0.00 \\
\hline$\varepsilon_{k}[\%]$ & 42.2 & 0.8 & 41.0 & 78.3 & 100.0 & 100.0 \\
\hline$y_{D, k}[\%]$ & 57.8 & 99.2 & 59.0 & 21.7 & 0.0 & 0.0 \\
\hline$y_{D, k}^{*}[\%]$ & 60.0 & 22.8 & 9.5 & 7.7 & 0.0 & 0.0 \\
\hline
\end{tabular}

Table 11. Conventional exergy analysis results for the ideal cycle 


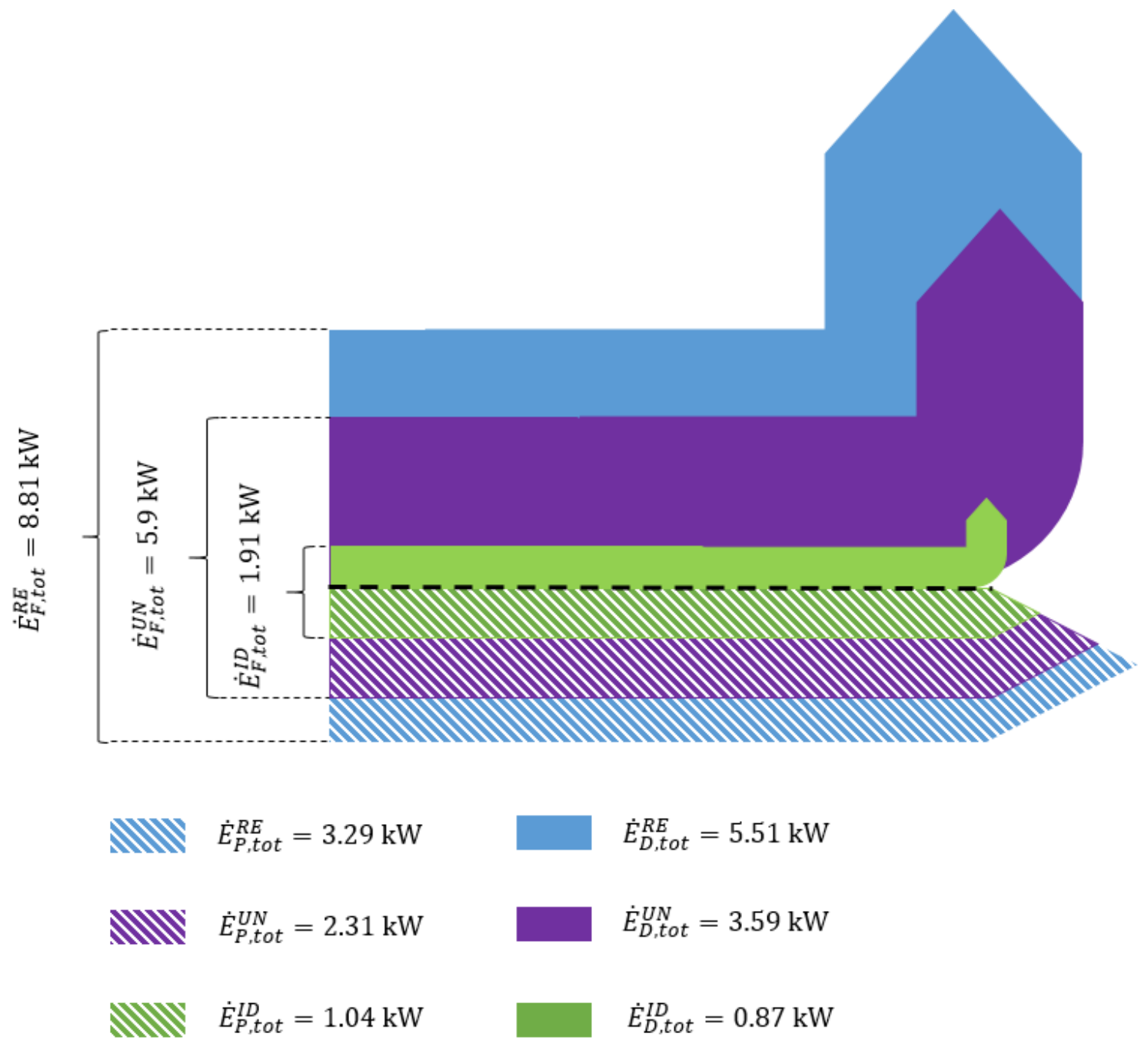

Figure 6. Exergy destruction, exergy of fuel and exergy of products for the real, unavoidable and ideal cycle configurations in the overall system

\section{Influence of off-design operating conditions}

The so-called off-design study evaluates exergy destruction away from design conditions. Unlike the previous study, ejector scale is not a degree of freedom but it is fixed to a reference size different from the optimum one. In other words the system has been designed to offer best performance in the reference engine conditions (2000 rpm, 50\% load), however, performance is investigated introducing different engine boundary conditions ( $2500 \mathrm{rpm}$ and $75 \%$ load). Operating conditions in a passenger vehicle are constantly changing in a standard driving behaviour so this approach has special significance.

The increase of engine load and speed translates into an increase in engine mass flow and exhaust thermal level as can be seen in Table 5. In principle, reference ejector is smaller than the one required to get best performance at $2500 \mathrm{rpm}$ and $75 \%$ load because engine drawn mass flow has increased but ejector size remains the same. Since ejector primary nozzle is working in critical conditions there is a limit on primary mass flow passing through ejector. As consequence, a surplus of heat on exhaust line exists. This effect causes a deterioration on exergy efficiency in generator, in fact, $\varepsilon_{g e}=44.5 \%$ and $\varepsilon_{g e}=19.7 \%$ in design and off-design analysis, respectively. This trend could be extended to the rest of engine operating points showing higher mass flow and exhaust thermal level. 
Fixed ejector size also has a negative impact on intake cooling because mass flow of the refrigerant at the cooling loop barely changes in comparison with reference case and intake mass flow (engine side) increases accordingly with exhaust mass flow. The aforementioned limitations lead to $T_{o, \text { in }}=9.3{ }^{\circ} \mathrm{C}$ and $T_{o, \text { in }}=14.1^{\circ} \mathrm{C}$ in design and off-design conditions, respectively.

\subsection{Advanced exergy analysis}

From the conventional exergy analysis and considering the reference engine working point of $2000 \mathrm{rpm}$ and $50 \%$ of load, it can be inferred that improvement priority should be focused on generator ( $55.8 \%$ of total exergy destruction considering the overall system) followed by ejector (32.5\% of overall exergy destruction). However, from the perspective of the advanced exergy analysis it must be noted that only $1.9 \mathrm{~kW}$ (34.6\% of overall exergy destruction) corresponds with the avoidable part in the overall system, that is, the part that could be reduced (Table 12). In this analysis, also generator and ejector are the main contributors so attention should be paid on them.

Generator improvement would bring a scarce benefit because exogenous avoidable part prevails. For this component, it must be noted that the endogenous avoidable part represents less than $1 \%$ of total exergy destruction because pinch point reduction between real and unavoidable cases does not provide a significant benefit. Particularly, the ejector plays a major role on exergy destruction at generator than the generator itself. Thus, an improvement of the ejector component would lead to a reduction of primary mass flow for the same cooling capacity and it would have a positive impact over exergy destruction at generator.

In view of the advanced exergy analysis results there is a substantial improvement potential in ejector component ( $41 \%$ of exergy destruction in this component corresponds to the avoidable part according to Figure 7), however, performance gap between ideal ejector and unavoidable ejector is significant due to the huge variance in entrainment ratio. This means that unavoidable part prevails (59\% of total exergy destruction in the ejector). Advanced exergy analysis also sheds light on element interactions. Almost all exergy destruction is due to ejector itself ( $99 \%$ of total exergy destruction in the ejector corresponds to the endogenous part). Splitting into endogenous/exogenous and avoidable/unavoidable parts it can be observed that endogenous avoidable part corresponds to $42 \%$ of total exergy destruction in the ejector. Hence, improving the ejector component considering technological limitations would lead to a reduction of $42 \%$ of ejector exergy destruction. It is also remarkable that exogenous unavoidable part of exergy destruction in this component shows negative values. This means that a deterioration in ejector in terms of exergy efficiency would occur if the rest of the components were upgraded to ideal conditions. However, these negative values are small. In summary, attention should be paid on ejector since improvement of this component may have an impact on ejector itself and the rest of the components.

According to the conventional exergy analysis condenser represents around $9 \%$ of total exergy destruction considering the overall system. Hence, it should be the third element under consideration. Exogenous exergy destruction is predominant ( $73 \%$ of total exergy destruction in the condenser) so irreversibilities occurring inside the condenser are influenced by the rest of the equipment. Moreover, this inefficiencies cannot be mitigated substantially overcoming 
technological constraints since they correspond to the unavoidable part. This is a consistent result since heat rejection to ambient conditions occurs irrespectively of the case under investigation and it is a source of inefficiencies. This is why endogenous avoidable part is only $9 \%$ of the total exergy destruction in the condenser.

The rest of elements have a small contribution to the overall system exergy destruction (only $2.5 \%$ of total exergy destruction). Among them, evaporator shows significant improvement potential because endogenous avoidable part represents $31 \%$ of its total exergy destruction. Endogenous unavoidable part is also significant (35\%) in the evaporator and both results indicate that a further reduction in pinch point would lead to a substantial reduction on exergy destruction in this element.

The results of the present paper point out that the ejector is the key element to improve overall cycle performance. This results are in agreement with results presented by Chen et al. (Chen, Havtun and Palm, 2015). Discrepancies have been found when computing the contribution of each element to total exergy destruction. In the present paper generator plays a major role since for an automotive application thermal level of the heat source (engine exhaust) is considerably higher than other typical cycles analysed in the scientific literature. The relevance of the generator when the system is driven by a heat source with a relatively high thermal level is also highlighted by Ustaoglu et al. (Ustaoglu et al., 2017).

\begin{tabular}{|c|c|c|c|c|c|c|c|c|c|}
\hline Component & $\dot{E}_{D}$ & $\dot{E}_{D}^{E N}$ & $\dot{E}_{D}^{E X}$ & $\dot{E}_{D}^{A V}$ & $\dot{E}_{D}^{U N}$ & $\dot{E}_{D}^{E N, A V}$ & $\dot{E}_{D}^{E N, U N}$ & $\dot{E}_{D}^{E X, A V}$ & $\dot{E}_{D}^{E X, U N}$ \\
\hline Generator & 3.071 & 0.516 & 2.555 & 1.006 & 2.065 & 0.027 & 0.489 & 0.979 & 1.576 \\
\hline Evaporator & 0.096 & 0.196 & -0.101 & -0.008 & 0.104 & 0.092 & 0.104 & -0.100 & -0.001 \\
\hline Condenser & 0.510 & 0.139 & 0.371 & 0.162 & 0.348 & 0.048 & 0.091 & 0.114 & 0.258 \\
\hline Expansion valve & 0.025 & 0.157 & -0.132 & -0.002 & 0.027 & 0.130 & 0.027 & -0.132 & 0.000 \\
\hline Pump & 0.018 & 0.002 & 0.016 & 0.013 & 0.005 & 0.001 & 0.001 & 0.012 & 0.004 \\
\hline Ejector & 1.788 & 1.812 & -0.024 & 0.738 & 1.050 & 0.824 & 0.988 & -0.085 & 0.062 \\
\hline Overall system & 5.508 & 2.821 & 2.686 & 1.909 & 3.598 & 1.122 & 1.700 & 0.788 & 1.899 \\
\hline
\end{tabular}

Table 12. Advanced exergy analysis results (kW) 


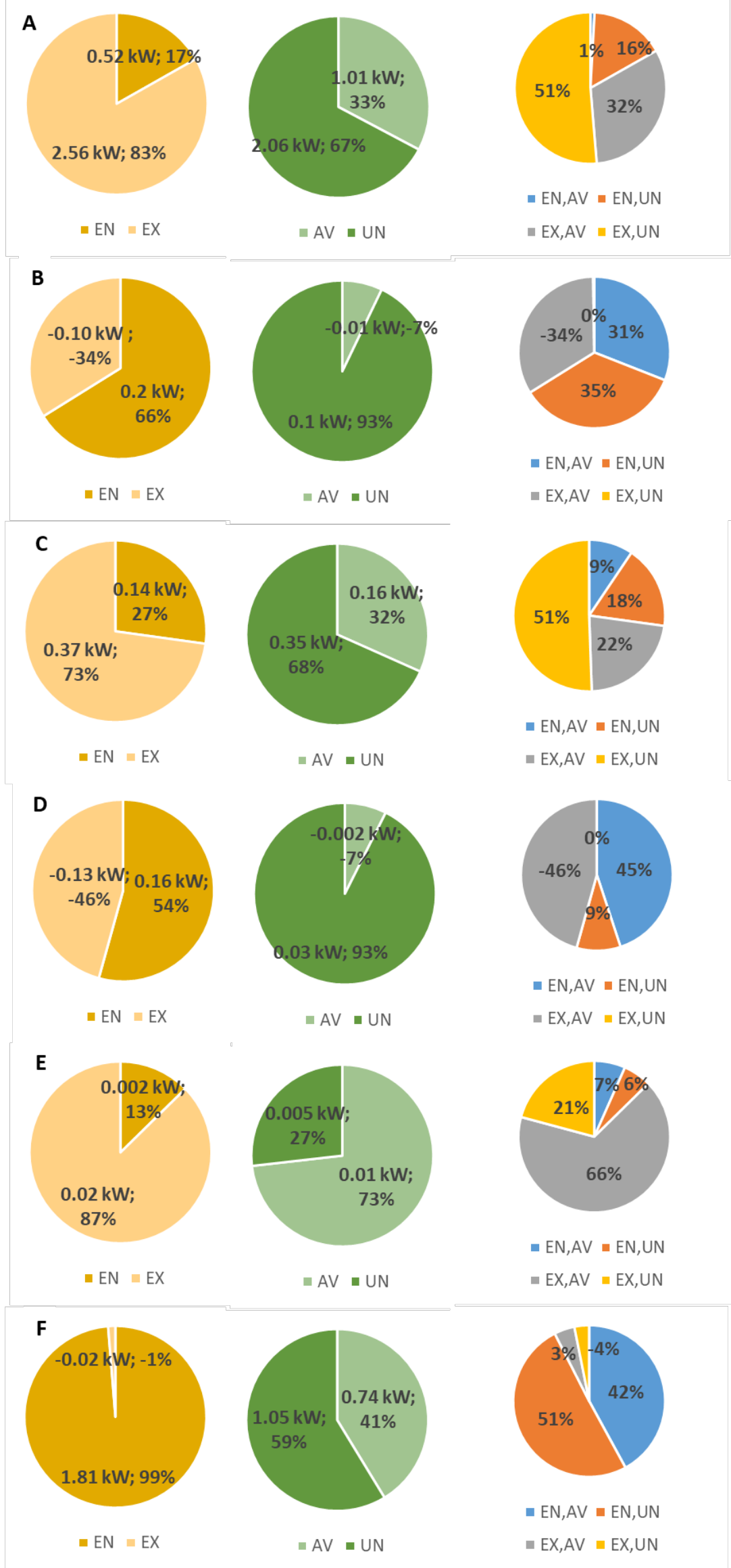


Figure 7. Advanced exergy analysis for: A) Generator, B) Evaporator, C) Condenser D) Expansion valve E) Pump F) Ejector. Left (endogenous vs exogenous), middle (avoidable vs unavoidable) right (advanced exergy splitting)

\section{CONCLUSIONS}

The present paper evaluates a conventional ejection cycle coupled to a $1.5 \mathrm{I}$ Diesel automotive engine for waste heat recovery. The objective of this cycle is to cool down the intake air mass flow of the engine to values lower than the ambient temperature by using the heat of the exhaust gases. The analysis performed in this article takes into account the perspective of a conventional and advanced exergy analysis. The following conclusions can be extracted from the results:

- According to the conventional analysis, in the cycle operating point that minimizes charge air temperature the generator is the main source of inefficiencies representing $55.8 \%$ of total exergy destruction, followed by ejector (32.5\%) and condenser (9.3\%). If the analysis is extended to all cycle feasible points (Figure 3, Figure 4 and Figure 5 ) it is observed that exergy destruction occur in generator or alternatively in ejector and condenser due to the mandatory heat rejection.

- From the perspective of the advanced exergy analysis, a total amount of $1.9 \mathrm{~kW}(34.6 \%$ of overall exergy destruction) corresponds to the avoidable part so there is a significant improvement potential. Focusing on the components with the highest contribution to the avoidable exergy destruction, ejector exogenous avoidable part represents $3 \%$ of exergy destruction in the ejector and $41 \%$ corresponds to the endogenous avoidable part. By contrast, the exogenous avoidable part is predominant in the generator (32\%) and the endogenous avoidable part is negligible $(<1 \%)$. Therefore, ejector enhancement would have a positive impact on ejector performance itself but also on the rest of the elements and the overall cycle. In fact, the system working in real conditions presents a low $\operatorname{COP}\left(C_{C O P}^{R E}=0.097\right)$ while the COP of the enhanced system within technological limitations is slightly higher $\left(\operatorname{COP}_{t h}^{U N}=0.147\right)$ and the COP of the idealized system is significantly improved $\left(C O P_{t h}^{R E}=0.604\right)$. It is also remarkable that performance gap between real ejector, the best ejector considering technological limitations and the ejector with an idealized performance is substantial. This difference can be quantified by means of ejector entrainment ratio $\left(\omega^{R E}=0.128, \omega^{U N}=0.198\right.$ and $\left.\omega^{I D}=0.886\right)$. Therefore, ejector is the key element to improve overall system efficiency.

- When the refrigeration system works in off-design conditions primary mass flow flowing through power loop is limited and this effect leads to a poor exergy efficiency on generator due to the surplus of heat available. The ratio between product and fuel exergy is 0.45 and 0.2 in design and off-design conditions, respectively. Therefore, high exhaust thermal level is under-exploited. Some additional actuators as a variable ejector geometry to adapt the ejector to the working conditions of the system could be an interesting solution to avoid the efficiency reduction in off-design conditions. 


\section{BIBLIOGRAPHY}

Aghaali, H. and Ångström, H. E. (2015) 'A review of turbocompounding as a waste heat recovery system for internal combustion engines', Renewable and Sustainable Energy Reviews. Elsevier, 49, pp. 813-824. doi: 10.1016/j.rser.2015.04.144.

Aly, S. E. (1988) 'Diesel engine waste-heat power cycle', Applied Energy, 29(3), pp. 179-189. doi: 10.1016/0306-2619(88)90027-X.

Aman, J., Henshaw, P. and Ting, D. (2019) 'Enhanced exergy analysis of a bubble-pump-driven LiCl-H2O absorption air-conditioning system', International Journal of Exergy, 28, p. 333. doi: 10.1504/IJEX.2019.099292.

Asgari, S., Noorpoor, A. R. and Boyaghchi, F. A. (2017) 'Parametric assessment and multiobjective optimization of an internal auto-cascade refrigeration cycle based on advanced exergy and exergoeconomic concepts', Energy. Elsevier Ltd, 125, pp. 576-590. doi: 10.1016/j.energy.2017.02.158.

Chen, J., Havtun, H. and Palm, B. (2015) 'Conventional and advanced exergy analysis of an ejector refrigeration system', Applied Energy. Elsevier Ltd, 144, pp. 139-151. doi: 10.1016/j.apenergy.2015.01.139.

Chen, W. et al. (2013) 'A 1D model to predict ejector performance at critical and sub-critical operational regimes', International Journal of Refrigeration. Elsevier, 36(6), pp. 1750-1761. doi: 10.1016/J.IJREFRIG.2013.04.009.

Cziesla, F., Tsatsaronis, G. and Gao, Z. (2006) 'Avoidable thermodynamic inefficiencies and costs in an externally fired combined cycle power plant', Energy, 31(10-11), pp. 1472-1489. doi: 10.1016/j.energy.2005.08.001.

Dolz, V. et al. (2012) 'HD Diesel engine equipped with a bottoming Rankine cycle as a waste heat recovery system. Part 1: Study and analysis of the waste heat energy', Applied Thermal Engineering. Elsevier Ltd, 36(1), pp. 269-278. doi: 10.1016/j.applthermaleng.2011.10.025.

Fallah, M. et al. (2016) 'Advanced exergy analysis of the Kalina cycle applied for low temperature enhanced geothermal system', Energy Conversion and Management. Elsevier Ltd, 108, pp. 190-201. doi: 10.1016/j.enconman.2015.11.017.

Galindo, J. et al. (2015) 'Brayton cycle for internal combustion engine exhaust gas waste heat recovery', Advances in Mechanical Engineering, 7(6), p. 168781401559031. doi: 10.1177/1687814015590314.

Galindo, J. et al. (2015) 'Experimental and thermodynamic analysis of a bottoming Organic Rankine Cycle (ORC) of gasoline engine using swash-plate expander', Energy Conversion and Management. Elsevier Ltd, 103, pp. 519-532. doi: 10.1016/j.enconman.2015.06.085.

Galindo, J. et al. (2016) 'Advanced exergy analysis for a bottoming organic rankine cycle coupled to an internal combustion engine', Energy Conversion and Management. Elsevier Ltd, 126, pp. 217-227. doi: 10.1016/j.enconman.2016.07.080.

Galindo, J. et al. (2019) 'Thermodynamic Analysis and Optimization of a Jet Ejector Refrigeration Cycle Used To Cool Down the Intake Air in an Ic Engine', International Journal of Refrigeration. Elsevier Ltd, 103, pp. 253-263. doi: 10.1016/j.ijrefrig.2019.04.019. 
Gong, S. and Goni Boulama, K. (2015) 'Advanced exergy analysis of an absorption cooling machine: Effects of the difference between the condensation and absorption temperatures', International Journal of Refrigeration. Elsevier Ltd, 59, pp. 224-234. doi: 10.1016/j.jirefrig.2015.07.021.

Grazzini, G., Milazzo, A. and Piazzini, S. (2011) 'Prediction of condensation in steam ejector for a refrigeration system', International Journal of Refrigeration. Elsevier Ltd and IIR, 34(7), pp. 1641-1648. doi: 10.1016/j.ijrefrig.2010.09.018.

Gullo, P., Elmegaard, B. and Cortella, G. (2016) 'Advanced exergy analysis of a R744 booster refrigeration system with parallel compression', Energy. Elsevier Ltd, 107, pp. 562-571. doi: 10.1016/j.energy.2016.04.043.

Herrera, R. and Méndez, F. (2018) 'An advanced exergy analysis based on the dysfunction and malfunction methodology for a combined cycle power plant: A Mexican case study', International Journal of Exergy, 27(1), pp. 105-120. doi: 10.1504/JJEX.2018.093902.

Hsiao, Y. Y., Chang, W. C. and Chen, S. L. (2010) 'A mathematic model of thermoelectric module with applications on waste heat recovery from automobile engine', Energy. Elsevier Ltd, 35(3), pp. 1447-1454. doi: 10.1016/j.energy.2009.11.030.

Huang, B. J. et al. (1999) 'A 1-D analysis of ejector performance', International Journal of Refrigeration. Elsevier, 22(5), pp. 354-364. doi: 10.1016/S0140-7007(99)00004-3.

Kalghatgi, G. (2013) Fuel/Engine Interactions. SAE International. Available at: https://books.google.es/books/about/Fuel_engine_Interactions.html?id=SXWongEACAAJ\&redi r_esc=y (Accessed: 3 October 2018).

Lee, Y. and Jung, D. (2012) 'A brief performance comparison of R1234yf and R134a in a bench tester for automobile applications', Applied Thermal Engineering. Elsevier Ltd, 35(1), pp. 240242. doi: 10.1016/j.applthermaleng.2011.09.004.

$\mathrm{Li}, \mathrm{C}$. et al. (2015) 'Biomass boiler energy conversion system analysis with the aid of exergybased methods', Energy Conversion and Management. Elsevier Ltd, 103, pp. 665-673. doi: 10.1016/j.enconman.2015.07.014.

Little, A. B. and Garimella, S. (2011) 'a Review of Ejector Technology for Refrigeration Applications', International Journal of Air-Conditioning and Refrigeration, 19(01), pp. 1-15. doi: 10.1142/S2010132511000351.

Luján, J. M. et al. (2016) 'Potential of exhaust heat recovery for intake charge heating in a diesel engine transient operation at cold conditions', Applied Thermal Engineering, 105, pp. 501-508. doi: 10.1016/j.applthermaleng.2016.03.028.

McGovern, R. K., Prakash Narayan, G. and Lienhard, J. H. (2012) 'Analysis of reversible ejectors and definition of an ejector efficiency', International Journal of Thermal Sciences, 54, pp. 153166. doi: 10.1016/j.ijthermalsci.2011.11.003.

Morosuk, T. and Tsatsaronis, G. (2009) 'Advanced exergetic evaluation of refrigeration machines using different working fluids', Energy. Elsevier Ltd, 34(12), pp. 2248-2258. doi: 10.1016/j.energy.2009.01.006.

Morosuk, T. and Tsatsaronis, G. (2009) 'Advanced exergy analysis for chemically reacting systems - Application to a simple open gas-turbine system', International Journal of Thermodynamics, 12(3), pp. 105-111. doi: 10.5541/ijot.1034000245.

Nami, H., Nemati, A. and Jabbari Fard, F. (2017) ‘Conventional and advanced exergy analyses of 
a geothermal driven dual fluid organic Rankine cycle (ORC)', Applied Thermal Engineering. Elsevier Ltd, 122, pp. 59-70. doi: 10.1016/j.applthermaleng.2017.05.011.

Novella, R. et al. (2017) 'Thermodynamic analysis of an absorption refrigeration system used to cool down the intake air in an Internal Combustion Engine', Applied Thermal Engineering. Elsevier Ltd, 111, pp. 257-270. doi: 10.1016/j.applthermaleng.2016.09.084.

Payri, F. et al. (2015) 'A Challenging Future for the IC Engine: New Technologies and the Control Role', Oil \& Gas Science and Technology - Revue d'IFP Energies nouvelles. Technip, 70(1), pp. 15-30. doi: 10.2516/ogst/2014002.

Petrakopoulou, F. et al. (2012) 'Conventional and advanced exergetic analyses applied to a combined cycle power plant', Energy. Elsevier Ltd, 41(1), pp. 146-152. doi: 10.1016/j.energy.2011.05.028.

Reasor, P., Aute, V. and Radermacher, R. (2010) 'Refrigerant R1234yf Performance Comparison Investigation', International Refrigeration and Air Conditioning Conference at Purdue, pp. 1-7.

Şöhret, Y. et al. (2015) 'Advanced exergy analysis of an aircraft gas turbine engine: Splitting exergy destructions into parts', Energy, 90, pp. 1219-1228. doi: 10.1016/j.energy.2015.06.071.

Ustaoglu, A. et al. (2017) 'Enhanced exergy analysis of a waste heat powered ejector refrigeration system for different working fluids', International Journal of Exergy, 24(2-4), pp. 301-324. doi: 10.1504/IJEX.2017.087698.

Vaghela, J. K. (2017) 'Comparative Evaluation of an Automobile Air - Conditioning System Using R134a and Its Alternative Refrigerants', Energy Procedia. The Author(s), 109(November 2016), pp. 153-160. doi: 10.1016/j.egypro.2017.03.083.

Vučković, G. D., Stojiljković, M. M. and Vukić, M. V. (2015) 'First and second level of exergy destruction splitting in advanced exergy analysis for an existing boiler', Energy Conversion and Management, 104, pp. 8-16. doi: 10.1016/j.enconman.2015.06.001.

Zegenhagen, M. T. and Ziegler, F. (2015a) 'A one-dimensional model of a jet-ejector in critical double choking operation with R134a as a refrigerant including real gas effects', International Journal of Refrigeration. Elsevier Ltd and IIR, 55(2006), pp. 72-84. doi: 10.1016/j.jirefrig.2015.03.013.

Zegenhagen, M. T. and Ziegler, F. (2015b) 'Experimental investigation of the characteristics of a jet-ejector and a jet-ejector cooling system operating with R134a as a refrigerant', International Journal of Refrigeration. Elsevier Ltd and IIR, 56, pp. 173-185. doi: 10.1016/j.jirefrig.2015.01.001.

Zegenhagen, M. T. and Ziegler, F. (2015c) 'Feasibility analysis of an exhaust gas waste heat driven jet-ejector cooling system for charge air cooling of turbocharged gasoline engines', Applied Energy. Elsevier Ltd, 160, pp. 221-230. doi: 10.1016/j.apenergy.2015.09.057. 